\title{
Glycemic Status and In-hospital Complications in Acute Ischemic Stroke
}

\author{
Hossain MA ${ }^{1}$, Hannan MA² Barua R ${ }^{3}$, Hossain $\mathrm{MS}^{4}$, Ahmed $\mathrm{SU}^{5}$, Sina $\mathrm{H}^{6}$, Jahan $\mathrm{M}^{7}$
}

Conflict of Interest: None

Received: 13 August 2015

Accepted: 22 November 2016

www.banglajol.info/index.php/JSSMC

Key Words:

Acute ischemic stroke, Hyperglycemia, Euglycemia, Length of hospital stay.

\begin{abstract}
:
Although on-admission high glycemic status in acute ischemic stroke (AIS) patients is associated with poor in-hospital outcome, the impact of on-admission different glycemic status in AIS is less clear. This prognostic cohort study was aimed to evaluate the association of on-admission high glycemic status with in-hospital complications of AIS patients. This study was conducted by measurement of random blood glucose ( $R B G$ ) in 90 AIS patients within 24 hours of hospitalization. The patients were divided into three groups based on their RBG in mg/dl: Group A <120, Group $B$ 120-180 and Group $C>180$. The average age was 59 years and $35.6 \%$ patients were diabetic. In AIS patients, higher RBG was associated with increased in-hospital complications regardless of a history of diabetes mellitus ( $p=0.047,0.040,0.003$ and 0.015 for urinary tract infection, bed sore, electrolyte imbalance and mixed complications respectively). Optimal glucose targets in hospitalized patients with AIS are currently undetermined. Glycemic and nonglycemic interventions should be studied for their impact on in-hospital complications and cost.
\end{abstract}

[J Shaheed Suhrawardy Med Coll 2016; 8(2): 44-48] DOI: http://dx.doi.org/10.3329/jssmc.v8i2.37242

\section{Introduction}

Stroke is usually characterized by rapid onset of focal neurological deficit due to infarction or hemorrhage lasting more than 24 hours. ${ }^{1}$ The definition of stroke is clinical and laboratory studies including brain imaging are used to support the diagnosis. ${ }^{2}$ It is a major cause of death and disability worldwide. ${ }^{3}$ Countries of low and middle income have the largest burden of stroke, accounting for more than $85 \%$ of stroke mortality worldwide, but few reliable data are available to identify risk factors for stroke in most of these regions. ${ }^{4}$

To reduce burden of stroke patients, modifiable risk factors should be identified that could reduce the incidence of

1. Dr. Md. Amir Hossain, Assistant Professor of Neurology, National Institue of Neurosciences \& Hospital, Dhaka

2. Professor M. A. Hannan, Professor \& Chairman, Department of Neurology, Bangabandhu Sheikh Mujib Medical University, Dhaka,

3. Dr. Ripon Barua, Assistant Professor, Department of Microbiology, Faridpur Medical College, Faridpur,

4. Dr Mohammed Shahadat Hossain, Assistant Professor, Department of Medicine, Faridpur Medical College, Faridpur,

5. Dr Sharif Uddin Ahmed, Assistant Professor of Neurology, Jessore Medical College, Jessore,

6. Dr. Hashmi Sina, Assistant Professor of Neurology, Dhaka Medical College, Dhaka,

7. Dr. Merina Jahan, Lecturer, Dhaka Medical College, Dhaka.

Correspondene: Dr. Md. Amir Hossain, Assistant Professor of Neurology, National Institute of Neurosciences \& Hospital, Dhaka. Cell: +8801711382650, E-mail: amir.dr@gmail.com acute ischemic stroke (AIS). Multiple independent risk factors for AIS include hypertension, diabetes mellitus (DM), smoking, dyslipidemia, atrial fibrillation (AF), coronary artery disease, congestive heart failure etc. ${ }^{3}$ The role of DM as a risk factor for AIS is well-established. But the impact of different glycemic status on admission, both diabetic and non-diabetic, on stroke outcome is not well evaluated. As reported by Frederic, $11.3 \%$ of cases of stroke gave history of DM when compared with $2 \%$ in the general population. The incidence of DM was found to be twice as high in patients admitted to hospital with any type of stroke than in patients with other neurologic diseases. ${ }^{5}$ The increased risk of stroke in DM and the increased prevalence rate of stroke in DM as compared to the general population was confirmed by a study done by Wolf et al. Diabetics as well as patients with stress hyperglycemia have severe stroke ${ }^{6,7}$ was twice that of the general population. Glucose tolerance also deteriorates with age. ${ }^{8}$ Multivariate studies also show that blood glucose is a significant predictor of death. ${ }^{9}$

Increased blood glucose concentration at or around the time of a cerebral ischemic event may worsen outcome; even mild hyperglycemia $(6.6 \mathrm{mmol} / \mathrm{l})$ may result in increased brain damage and delayed recovery. Studies in rats showed that insulin improved the functional recovery from brain ischemia, probably through its effects on 
glucose and lactate levels. ${ }^{10}$ Hyperglycemia causes multiple medical complications like sepsis, urinary tract infection, respiratory tract infection, myocardial infarction etc. These complications cause deterioration of the stroke patients. Admission hyperglycemia, whether or not with known diabetes, is closely associated with adverse clinical outcomes in stroke patients. Hospital-induced blood glucose elevations (stress hyperglycemia) is also strongly linked to a poor inpatient prognosis as well higher average daily glucose levels lead to longer hospital stay and increase cost of care. ${ }^{9}$

Such type of study was not previously performed in Bangladesh. So glycemic target of our context is necessary to be fixed. So, this study was conducted to evaluate the association of on-admission high glycemic status with inhospital complications of AIS patients to provide necessary informations for proper management of different glycemic levels in AIS patients.

\section{Materials and Methods}

This prognostic cohort study was conducted in the department of Neurology of Bangabandhu Sheikh Mujib Medical University (BSMMU), Dhaka, Bangladesh during January 2013 to December 2013 and received prior approval from Ethical Review Committee of BSMMU and all participants gave informed written consent. All collected data were checked, edited and analyzed by using computer based SPSS software version 16.0. Samples were collected purposively. Data were presented by frequency distribution and percentage. Parametric data was expressed in mean \pm SD. Categorical data was evaluated by Chi square test. Significance was defined by $\mathrm{p}$ value d" 0.05 .

A total of 90 AIS patients admitted in the Neurology department of BSMMU were included in this study. Sampling technique was purposive. Patients presented with first ever ASI, confirmed by CT scan/MRI of brain from 01 day to 02 weeks were enrolled in this study. Age below 18 or above 75 years, hemorrhagic stroke, recurrent ischemic stroke, patients of venous thrombosis, cardioembolic events - AF, (Myocardial infarction) MI (within 6 weeks of acute stroke), prosthetic heart valve, endocarditis, valvular heart disease, any persistent hypercoagulable state, pregnancy, vasculitis etc and patients taken injectable glucose within last 8 hours of sample collection were excluded from the study.

After selection of subjects detailed history, clinical examinations and all other informations were taken in a prescribed data collection form. Relevant baseline investigations (e.g- complete blood count, urine $\mathrm{R} / \mathrm{M} / \mathrm{E}$ etc.) were performed. Imaging study (CT/MRI) was done for diagnosis and categorization of stroke. AIS subtype is defined by Oxfordshire Community Stroke Project classification (OCSP) criteria. Cerebral infarctions were divided into the following clinical categories: total anterior circulation infarcts (TACI), partial anterior circulation infarcts (PACI), lacunar infarcts (LACI), and posterior circulation infarcts (POCI). Blood for glucose measurement was taken within 24 hours of admission and was sent to Biochemistry department of BSMMU. Glucose was measured by Hexokinase method by spectrophotometrically at $340 \mathrm{~nm}$. According to blood glucose level all AIS patients were categorized into three groups Group A ( $<120 \mathrm{mg} / \mathrm{dl})$, Group B (120-180 mg/dl), Group C $(>180 \mathrm{mg} / \mathrm{dl})$.

Modified Rankin Scale (mRS) was measured to see functional outcomes at fourteenth day of stroke. Patients were followed up every day to see any in-hospital medical complications eg. Respiratory Tract Infection (RTI), Urinary Tract Infection (UTI), Bed sore, Electrolyte Imbalance (Sodium or Potassium abnormalities), MI. Diagnosis of this complications were made by clinical findings, expert opinion and appropriate laboratory reports like Urine R/E and C/S for UTI, Chest X ray and Sputum C/ S for RTI, ECG or Troponin I for MI, Serum Electrolytes, ddimer, duplex study of lower limb vessels, Stool R/E etc. Length of hospital stay (LOHS) was measured from admission to discharge day of the patient.

\section{Results}

Out of the 90 AIS patients, majority 36(40\%) were belonged to age group of 61-70 years. The mean age was found 59 years with range from 30 to 75 years (Table I).

\section{Table I}

Distribution of the study patients by age $(n=90)$

\begin{tabular}{lcc} 
Age (in year) & Number of patilents & Percentage \\
\hline d"'40 & 7 & 7.8 \\
$41-50$ & 9 & 10.0 \\
$51-60$ & 34 & 37.8 \\
$61-70$ & 36 & 40.0 \\
$71-75$ & 4 & 4.4 \\
Mean \pm SD & 59.01 & \pm 9.87 \\
Range (min, max) & $(30$ & $, 75)$ \\
\hline
\end{tabular}

It was observed that more than half (54\%) were male and $41(46 \%)$ were female. Male to female ratio was 1.2:1. It also showed that $49(54 \%)$ patients came from rural area and $41(46 \%)$ came from urban area.

This study revealed that $32(35.6 \%)$ patients had diabetes mellitus (DM). Among the diabetic patients 20(62.5\%) had diabetes for less than 5 years and $12(37.5 \%)$ for e" 5 years (Table II). This study showed that more than half (53.3\%) patients belonged to Group C (>180 mg/dl). The mean random blood glucose was found $205 \mathrm{mg} / \mathrm{dl}$ (Table III). 
Table II

\begin{tabular}{|c|c|c|}
\hline \multicolumn{3}{|c|}{$\begin{array}{c}\text { Distribution of the study patients by history of } \\
\text { Diabetes Mellitus }(n=90)\end{array}$} \\
\hline Diabetes Mellitus & Number of patients & Percentage \\
\hline No & 58 & 64.4 \\
\hline Yes & 32 & 35.6 \\
\hline \multicolumn{3}{|l|}{ Duration of DM } \\
\hline$<5$ years & 20 & 62.5 \\
\hline$\geq 5$ years & 12 & 37.5 \\
\hline
\end{tabular}

Table III

\begin{tabular}{lcc}
$\begin{array}{l}\text { Distribution of the patients by Random Blood Glucose } \\
(n=90)\end{array}$ & Percentage \\
$\begin{array}{l}\text { Random Blood } \\
\text { Glucose }(\mathrm{mg} / \mathrm{dl})\end{array}$ & $\begin{array}{c}\text { Number of } \\
\text { patients }\end{array}$ & \\
\hline Group A $(<120)$ & 14 & 15.6 \\
Group B $(120-180)$ & 28 & 31.1 \\
Group C $(>180)$ & 48 & 53.3 \\
Mean \pm SD & 205 & \pm 66.2 \\
Range (min, max $)$ & $(96.2$ & $, 392)$ \\
\hline
\end{tabular}

Note: DM- diabetes mellitus.

Table IV

Comparison between Random Blood Glucose with different in-hospital complications ( $n=90)$

In hospital complications

Random Blood Glucose (mg/dl)

\begin{tabular}{|c|c|c|c|c|c|c|c|c|}
\hline & \multirow[b]{2}{*}{$\mathrm{n}$} & \multicolumn{2}{|c|}{$\begin{array}{c}\text { Group A }<120 \\
(\mathrm{n}=14)\end{array}$} & \multicolumn{2}{|c|}{$\begin{array}{c}\text { Group B } 120-180 \\
(\mathrm{n}=28)\end{array}$} & \multicolumn{2}{|c|}{$\begin{array}{c}\text { Group C }>180 \\
(n=48)\end{array}$} & \multirow[t]{2}{*}{$\begin{array}{c}\mathrm{P} \\
\text { value }\end{array}$} \\
\hline & & $\mathrm{N}$ & $\%$ & $\mathrm{n}$ & $\%$ & $\mathrm{n}$ & $\%$ & \\
\hline Gastroenteritis & 4 & 0 & 0.0 & 1 & 25.0 & 3 & 75.0 & $0.585^{\mathrm{n}}$ \\
\hline UTI & 16 & 1 & 6.25 & 2 & 12.5 & 13 & 81.25 & $0.047^{\mathrm{s}}$ \\
\hline RTI & 16 & 1 & 6.2 & 4 & 25.0 & 11 & 68.8 & $0.335^{\mathrm{ns}}$ \\
\hline Bed sore & 3 & 2 & 66.7 & 0 & 0.0 & 1 & 33.3 & $0.040^{\mathrm{s}}$ \\
\hline Electrolyte Imbalance & 2 & 2 & 100.0 & 0 & 00.0 & 0 & 00.0 & $0.003^{\mathrm{s}}$ \\
\hline MI & 1 & 0 & 0.0 & 0 & 0.0 & 1 & 100.0 & $0.642^{\mathrm{ns}}$ \\
\hline Others/Mixed complication & 12 & 0 & 0.0 & 1 & 8.3 & 11 & 91.7 & $0.015^{\mathrm{s}}$ \\
\hline
\end{tabular}

Note: $\mathrm{s}=$ significant; $\mathrm{ns}=$ not significant. UTI- Urinary Tract Infection, RTI- Respiratory tract infection, MI- Myocardial infarction.

This present study results showed that UTI was found in 16 patients among them $1(6.25 \%)$ patient was in Group A, $2(12.5 \%)$ patients in Group B and 13(81.25\%) patients in Group C. Bed sore was found in 3 patients among them 2(66.7\%) patients were in Group A and 1(33.3\%) patient in Group C. Electrolyte Imbalance was found in 2 patients among them 2(100.0\%) patients were in Group A. Others/ Mixed complications were found in 12 patients among them $1(8.3 \%)$ patient was in Group B and $11(91.7 \%)$ in Group C. Above mentioned complications were statistically significant $(\mathrm{p}<0.05)$ but other complications were not statistically significant $(\mathrm{p}>0.05)$ compared with random blood glucose (Table IV).

\section{Discussion}

Frequency of stroke rises exponentially with increasing age. ${ }^{11}$ Majority of the study subject (40\%) were in seventh decade and the mean age was 59 years varied from 30 to 75 years (Table I). Similarly Hossain et al. in Faridpur Medical
College showed highest incidence of stroke was between the sixth and seventh decade. ${ }^{12}$ Kundu et al. in a Bangladeshi study showed $16 \%$ were young stroke (age $<40$ years) and most patients (54\%) were at and above 60 years of age $\mathrm{e}^{13}$. Basu et al. obtained that median age was 60 years, mean age $60 \pm 13$ years varied from 25-88 years, which is closely resembled with the present study. ${ }^{14}$ On the other hand, Gentile et al. showed the mean age was $65.7 \pm 13.6$ years varied from 20 to 101 years. ${ }^{3}$ In another study Bhatt and Rizvi found the average age of ASI patients was 67.8 years, which are higher with the current study, this may be due to increased life expectancy, and geographical influences may have significant impacts to developed ASI of their study patients. ${ }^{15}$

In this current study it was observed that ASI was predominant in male subjects, where $54 \%$ and $46 \%$ patients were male and female respectively and male to female ratio was 1.2:1. Similar observations regarding the sex incidence 
were also made by Basu et al. where they found $57.0 \%$ were male and $43.0 \%$ were female ${ }^{14}$. However, Gentile et al. and Bhatt and Rizvi were found $55.0 \%$ and $57.0 \%$ patients were female respectively. ${ }^{3,15}$ More than a half (54\%) of the patients attended from rural area and $46 \%$ came from urban. These findings are almost similar of the study done by Hossain et al. ${ }^{12}$ The reason of higher percentage of ASI in rural patients might be that, lack of consciousness regarding blood glycemic status due to low economical condition.

Considering socio-economic status, the lower-middle income group (monthly income BDT 7000-27000) comprised the majority $(77.7 \%)$. This result correlated with the study by Hart CL et al. which concluded that poor socioeconomic circumstances was associated with greater risk of stroke, which was also found in other studies. ${ }^{16,17,18}$ But this study disagreed with the study of Chapman et al. which showed the incidence of stroke was high among the high-income group. ${ }^{19}$

This study findings showed that more than one third (35.6\%) of the patients had DM and among them $20(62.5 \%)$ had DM for less than 5 years and $12(37.5 \%)$ for e" 5 years (Table II). Basu et al. and Bhatt and Rizvi showed 26.0\% and $51.4 \%$ had a known history of DM respectively. ${ }^{14,15}$ Stollberger et al. in 2005 found that $30 \%$ patients had a history of DM. ${ }^{20}$ Gentile et al. obtained DM 39.0\% in their study patients. ${ }^{3}$ Hossain et al. showed $21 \%$ DM in stroke patients at Faridpur Medical College. ${ }^{12}$ Kundu et al. showed DM is found in 99 (20\%) patients. ${ }^{13}$ And of these 99 patients only 57 (12\%) patients were known diabetic and the remaining patients were labeled as diabetic after admission. More than half $(53.3 \%)$ of the patients had RBG level $>180 \mathrm{mg} / \mathrm{dl}$ and the mean RBG was found 205 $\mathrm{mg} / \mathrm{dl}$, varied from $96.2-372 \mathrm{mg} / \mathrm{dl}$ (Table III). Similarly, Bhatt and Rizvi showed mean RBG was $213.6 \mathrm{mg} / \mathrm{dl}$, which is comparable with the current study. ${ }^{15}$

In this study, 54 (60\%) patients developed complications, out of those six patients in Group A, eight patients in Group B and forty patients in Group C. These complications were significantly $(\mathrm{p}<0.05)$ related with $\mathrm{RBG}$ level. In this series it was observed that UTI was found in 16 patients among them 1(6.25\%) patient was in Group A, 2(12.5\%) patients in Group B and 13(81.25\%) patients in Group C. Bed sore was found in 3 patients among them 2(66.7\%) patients were in Group A and 1(33.3\%) in Group C. Electrolyte Imbalance was found in 2 patients among them $2(100.0 \%)$ patients were in Group A. Others/Mixed complications were found in 12 patients among them 1(8.3\%) patient was in Group B and 11(91.7\%) in Group C. Above mentioned complications were statistically significant $(p<0.05)$ but other complications were not statistically significant ( $\mathrm{p}>0.05$ ) compared with RBG (Table IV). Stollberger et al. at Austria studied 992 patients of stroke where normoglycemic group had $12 \%$, hyperglycemic group had 19\% UTI $(\mathrm{p}<0.003)$, mixed complications in normoglycemic group 29\%, hyperglycemic group 36\% $(\mathrm{p}<0.01)$, but RTI in normoglycemic group 14\%, hyperglycemic group $13 \%$ $(p=0.79) .{ }^{20}$ These findings are similar with current study.

\section{Conclusion}

Both diabetes and atherosclerotic stroke are major health concerns in communities worldwide. Our observation at a large urban teaching hospital shows the average RBG level during early hospitalization, regardless of a known diagnosis of DM, to be a significant risk factor for length of time spent in the hospital and major in-hospital medical complications in patients with AIS. A higher level portends a worse clinical prognosis and longer inpatient stay. Elevated RBG was found in most of the AIS patients. Most of the AIS patients with elevated RBG had developed inhospital complications. Optimal glucose targets in hospitalized patients with AIS are currently undetermined. Glycemic and nonglycemic interventions should be studied for their impact on in-hospital complications and cost.

\section{References}

1. Fauci AS, Braunwald E, Kasper DL, Hauser SL, Longo DL, Jameson JL. Cerebrovascular disease. In: Harrison's Principles of Internal Medicine 17th Edition, McGraw Hill, New York. 2008.

2. Smith WS, Joey D, English S. Cerebrovascular disease. In: Harrison's Principles of Internal Medicine 18th Edition, McGraw Hill, New York. 2011; 3270-94.

3. Gentile NT, Seftchick MW, Huynh T, Kruus LK, Gaughan J. 'Decreased mortality by normalising Blood Glucose after Acute Ischemic Stroke'. Acad Emerg Med. 2006; 13: 17480 .

4. Williams LS, Rotich J, Fineberg N, Espay A, Bruno A, Fineberg $\mathrm{SE}$, et al. Effects of admission hyperglycemia on mortality and costs in Acute Ischemic Stroke. Neurology. 2002; 59: $67-71$.

5. Frederic MW. Cerebrovascular disease. In: Cardiac and Vascular Disease Conn HLJR and Horwitzo (eds). Lea and Febiger, Philladelphia. 1971; 1473-99.

6. Wolf PA, Cobb JL, Agostine D. Epidemiology of stroke; Stroke $2^{\text {nd }}$ Edition, Barnett HJM and Mohr JP (eds). Churchill Livingstone, Edinburgh. 1992; 3-27.

7. Houseley E. Definition of risk factors in stroke; Stroke Gillingam FJ and Mawdsley C (eds), Churchill Livingstone, New York. 1976; 251-60.

8. Davidson MB. The effect of ageing on carbohydrate metabolism. A review of the English literature and a practical approach to the diagnosis of diabetes mellitus in the elderly. Metabolism. 1979; 28: 688-705.

9. Sharma AK, Mahrotra TN, Goel VK. Clinical profile of stroke in relation to glycemic status of patients. $J$ Assoc Physicians India. 1996; 44 (1): 19-21. 
10. Weir CJ, Murray GD, Dyker AG, Lees KR. Is hyperglycemia an independent predictor of poor outcome after acute stroke? Results of a long-term follow up study. BMJ. 1997; 314: 1303-1306.

11. Botania R, Beaglegore R, North JDK. Events, Incidence and case fatality rates of cerebrovascular disease in Auckland, New Zealand. Am J Epidemiology. 1984; 120: 236-43.

12. Hossain AM, Ahmed NU, Rahman M, Islam MR, Sadhya G, Fatema K. Analysis of Sociodemographic and Clinical Factors associated with Hospitalized Stroke Patients of Bangladesh. Faridpur Med. Coll. J. 2011; 1: 19-23.

13. Kundu NC, Ahmed Q, Sen M. 'Study of Stroke and its Risk Factors Among Admitted Patients in A Tertiary Level Hospital'. Bangladesh Journal of Neuroscience. 2010; 26: 86-91.

14. Basu S, Sanyal D, Roy K, Bhattacharya K. 'Is post-stroke hyperglycemia a marker of stroke severity and prognosis: A pilot study'. Neurology Asia. 2007; 12: 13-19.

15. Bhatt H, Rizvi AA. 'Average Inpatient Glucose Levels during the first 72 hours Clinical Outcomes, and Length of Hospital
Stay in Patients with Acute Ischemic Stroke'. Int J Diabetes \& Metab. 2010; 18: 13-17.

16. Hart CL, Hole DJ, Smith GD. Influence of socioeconomic circumstance in early and later life on stroke risk among men in a Scottish cohort study. Stroke. 2000; 31(9): 2093-97.

17. Casper M, Wing S, Strogatz D. Variation in the magnitude of black- white differences in stroke mortality by community occupational structure. J Epidemiol Community Health. 1991; 45: 02-307.

18. Shaper AG. Risk factors for stroke in middle age British men. BMJ. 1991; 302: 1111-16.

19. Chapman J. Epidemiology of vascular lesions affecting the central nervous system: The occurrence of stroke in a sample population under observation for cardiovascular disease. Am J Public Health. 1966; 55: 191-01.

20. Stollberger C, Exner I, Finsterer J, Slany J, Steger C. 'Stroke in diabetic and non-diabetic patients: Course and prognostic value of admission serum glucose'. Annals of Medicine. 2005; 37: $357-64$. 